\title{
Cost-effective Ultrasonic Extraction of Bioactive Polyphenols from Vine and Wine Waste in Serbia
}

\author{
V.N. Radovanović ${ }^{*}$, M. Andjelković ${ }^{2}$, B. Arsić ${ }^{3}$, A. Radovanović ${ }^{4}$, L. Gojković-Bukarica ${ }^{5}$
}

(1) Department of Geography, Faculty of Sciences and Mathematics, University of Niš, Višegradska 33, 18000 Niš, Republic of Serbia

(2) Department of Chemistry, Faculty of Sciences and Mathematics, University of Niš, Višegradska 33, 18000 Niš, Republic of Serbia

(3) Department of Mathematics, Faculty of Sciences and Mathematics, University of Niš, Višegradska 33, 18000 Niš, Republic of Serbia

(4) Faculty of Chemistry, University of Belgrade, Studentski trg 12-16, 11000 Belgrade, Republic of Serbia

(5) Faculty of Medicine, University of Belgrade, Dr Subotića 8, 11000 Belgrade, Republic of Serbia

Submitted for publication: September 2018

Accepted for publication: March 2019

Keywords: Vine and waste by-products, ultrasonic extraction, polyphenols, antimicrobial activity, antioxidant activity

By using cost-effective ultrasonic extraction techniques, bioactive phenolic extracts were obtained from Merlot and Vranac (Vitis vinifera L.) vine and wine waste produced in Serbian wineries. These wastes include vine leaves, grape pomace, seeds, skins and stems, which can find further use in the food and pharmacology industries as preservatives against microbes. The extracts showed strong scavenging free radical activity $\left(\mathrm{EC}_{50}\right.$ from 0.37 to $\left.2.02 \mathrm{mg} / \mathrm{L}\right)$, which was in very good correlation with the total polyphenol content. Strong antimicrobial activity was found against six Gram-positive and five Gram-negative bacterial strains, and against the yeast Candida albicans. The principal component and agglomerative hierarchical clustering analyses performed were shown to be good for grouping and distinguishing the results from the vine and wine by-products (leaves and seeds) from both investigated grape varieties based on the content of various polyphenolic classes, and antioxidant and antimicrobial activities. The valorisation of the grape by-products is consistent with the concept of a sustainable and environmentally oriented wine industry and provides an important economic advantage.

\section{INTRODUCTION}

Grape cultivation is one of the main extended agro-economic activities in the world. In 2014, a total surface area of 7535 917 ha was under vineyards throughout the world, with global table grape production at 267167.581 (in 1000 quintels (ql)) and world wine production at 269363.753 (in $1000 \mathrm{hL}$ ) (OIV, 2018). The Republic of Serbia is one of the major producers and consumers of grapes and wines in the Western Balkan. During wine production, significant quantities of grape byproducts (seeds, skins, stems and residual pulp) are generated (Andjelković et al., 2013; Christ \& Burrit, 2013; Brenes et al., 2016). The amounts of grape pomace generated from winemaking depend on the grape cultivar, the fermentation process and the pressing process (Abarghuei et al., 2010; Dwyer et al., 2014; Cuccia, 2015; Lingua et al., 2016a). Grape seeds represent $2 \%$ to $5 \%$ of the grape weight and constitute approximately $38 \%$ to $52 \%$ of solid grape pomace (Brenes et al., 2016). In recent years, it has been estimated that $3 \%$ of pomace produced is reused for animal feed, and for the production of brandy and oil (obtained from seeds); other applications are fertiliser (obtained from the pomace) and a possibility of being used to improve thermal insulation in building construction (Dwyer et al., 2014; Muñoz et al., 2014; Santos et al., 2016).

Plants produce polyphenols as a response to the negative impacts of the environment (UV radiation, various pathogens, fungi, etc.). All plant parts contain phytochemicals such as phenols in different quantities, depending on the stage of plant development and the environmental influence. By using an ultrasonic extraction technique (Andjelković et al., 2014) for a short extraction period $(15 \mathrm{~min})$ at room temperature and with a small concentration of solvent, phenolic extracts were obtained from different parts of vine by-products.

It is known that grapes are rich in polyphenols, which are very important compounds for human health because of their antioxidant, anti-cancer, anti-inflammatory, antimicrobial and other biological properties (Jayaprakasha et al., 2003; Özkan et al., 2004; Baydar et al., 2006; Anastasiadi et al., 2009; Katalinić et al., 2010; Radovanović et al., 2012).

\footnotetext{
*Corresponding author: E-mail address: blaga_radovanovic@yahoo.co.uk

Acknowledgements: We would like to thank the Ministry of Education and Science of the Republic of Serbia, for support through projects No. 31020 and No. 174007
} 
During the process of wine production from grapes, a significant amount of phenolic compounds pass into the wine, but a certain level of these compounds also remains in the pomace (Ky et al., 2014). Brenes et al. (2016) show that the composition of pomace can be different depending on the grape variety, location, fertilisation conditions, soil and harvest period, and that these differences give different application possibilities. The phenolic composition of the pomace (Özkan et al., 2004), stalks (Souquet et al., 2000; Spigno et al., 2007), seeds (Baydar et al., 2006; Baiano \& Terracone, 2011), skins (Bartolome et al., 2004; Poudel et al., 2008) and leaves (Monagas et al., 2006; Dani et al., 2010) of different grape varieties have been well documented. The antimicrobial activity of their extracts has barely been studied (Jayaprakasha et al., 2003; Özkan et al., 2004; Baydar et al., 2006), although there are published reports on their antioxidant activity (Parry et al., 2011; Rockenbach et al., 2011; Lingua et al., 2016a, 2016b).

Because of the increased interest in the use of natural rather than synthetic compounds in the food industry, grape polyphenols are being investigated for use as a functional food (dietary fibre), in food processing (biosurfactants) and as supplements (grape pomace power) (Shinagawa et al., 2015). In this study, statistical analyses of correlations among the contents of various classes of polyphenolic compounds, determined using HPLC, and the antioxidant and antimicrobial activities of grape seeds, skins, stems and leaves from the Merlot and Vranac (Vitis vinifera L.) varieties, were investigated against six Gram-positive and five Gramnegative bacterial strains, and the yeast Candida albicans. Ultrasound extraction was used because it has been proven to require less time giving higher yields than conventional solvent extraction (Rostagno et al., 2003; Wang et al., 2008; Andjelković et al., 2014).

\section{MATERIAL AND METHODS}

\section{Reagents and chemicals}

Solvents were obtained from Merck (Darmstadt, Germany). Standard phenolic compounds and 2,2'-diphenyl-1picrylhydrazyl (DPPH) free radical were supplied by Sigma Chemical Co. (St. Louis, MO). Chloramphenicol, streptomycin and tetracycline were acquired from a local pharmacy. Nutrient agar and nutrient broth were purchased from Merck. The reagents used were of analytical quality.

\section{Samples}

The grape leaves of two varieties, viz. Merlot and Vranac (Vitis vinifera L.), were collected from the Serbia vineyard region in mid-October (2009 to 2012), after harvest. All samples were washed using distilled water at room temperature, and then frozen at $-20^{\circ} \mathrm{C}$. Before the extraction of seeds from the berries, the skin and pulp were separated by hand. Seeds and skins were dried at $60^{\circ} \mathrm{C}$, and measured until achieving a constant mass. Dried seeds and skin were mixed in a blender, and then used for the extractions.

During the harvest season (mid-October, 2009 to 2012), healthy leaves were collected from Vranac and Merlot, dried at $60^{\circ} \mathrm{C}$, mixed in the blender, and then used for the extraction. Pomace samples (side product after vinification of the investigated grape types) were also collected. Seeds, skins and stems from the pomace were separated by hand. Pomace samples and the separated seeds, skins and stems were dried at $60^{\circ} \mathrm{C}$, mixed in a blender, and then used for the extractions.

\section{Ultrasound-assisted extraction}

An ultrasound instrument (EI, Serbia) with a volume of $3 \mathrm{~L}$, a frequency of $40 \mathrm{kHz}$ and an input power of $500 \mathrm{~W}$ was used in the experiments. The samples $(1 \mathrm{~g})$ of dry grape leaves, stems and pomace, and the seeds and skins from the pomace, were ultrasonically extracted for $1 \mathrm{~h}$ with $40 \mathrm{~mL}$ of the solvent system, consisting of methanol:acetone:water:acetic acid (30:42:27.5:0.5), and then centrifuged (2 $500 \mathrm{x} g$ ) for 10 min (Andjelković et al., 2014). After treatment, extracts were centrifuged for $10 \mathrm{~min}$ at $2500 \mathrm{x} g$ and evaporated to dryness under a vacuum rotary evaporator and diluted in methanol to a concentration of $0.1 \mathrm{~g} / \mathrm{mL}$. Dry extract/initial dry mass (\%) was $9.64 \pm 0.36$ from the pomace, $16.14 \pm 0.22$ from the seeds, $12.03 \pm 0.21$ from the skins, $6.25 \pm 0.14$ from the stems, and $8.21 \pm 0.12$ from the leaf powder.

\section{Spectrophotometric analysis}

The total polyphenol content in the selected extract samples was determined according to the spectrophotometric method described previously (Mazza et al., 1999). The results are expressed as milligrams (mg) of gallic acid equivalents (GAE) per gram (g) of extract dry matter (DM).

\section{HPLC analysis}

The phenolic composition of the extracts was analysed by high-performance liquid chromatography (HPLC) after they were previously filtered through a $0.45 \mu \mathrm{m}$ pore size membrane filter. An Agilent Technologies 1200 chromatographic system, equipped with an Agilent photodiode array detector (DAD) 1200 with RFID tracking technology for flow cells and a UV lamp, an automatic injector and ChemStation software, was used for the determination of individual phenolic compounds. The phenolic compounds in the selected extract samples were determined according to the HPLC method described previously (Radovanović et al., 2012, 2016). The wavelengths for detection were 280 , 320,360 and $520 \mathrm{~nm}$ for UV and $275 / 322 \mathrm{~nm}\left(\lambda_{\mathrm{Ex}} / \lambda_{\mathrm{Em}}\right)$ for fluorescence-detection analysis. The identification of compounds was achieved by comparison of their retention times and spectral characteristics to original reference standard compounds and data in the literature (Iacopini et al., 2008). The results are presented as mg/g DM.

\section{Antioxidant activity}

The antioxidant activity of all the extracts was estimated by determining the free radical-scavenging activity of extracts using the DPPH free radical test described previously (Radovanović et al., 2010). The antioxidant assay is based on the measurement of the loss of DPPH colour by change in the absorbance at $515 \mathrm{~nm}$ caused by the reaction of DPPH with the tested sample. The reaction was monitored by a UV/ Vis spectrophotometer. The diluted extract and fresh $1 \times 10^{-4}$ M DPPH methanolic solution were put into a cuvette at room temperature. After the $20 \mathrm{~min}$ incubation period at room temperature, the absorbance was read against a blank (the 
absorbance of the diluted sample extract) at $515 \mathrm{~nm}$. Radical scavenging activity (RSA, \%) of each extract was calculated from the decrease in absorbance according to the following equation:

$\operatorname{RSA}(\%)=\left[\left(1-\mathrm{A}_{\text {sample }}-\mathrm{A}_{\text {blank }}\right) /\left(\mathrm{A}_{\text {control }}\right)\right] 100$

where $\mathrm{A}_{\text {control }}$ is the absorbance of the control reaction, $\mathrm{A}_{\text {blank }}$ is the absorbance of the diluted extract, and $\mathrm{A}_{\text {sample }}$ is the absorbance of the extract with DPPH radical. The RSA was plotted against the extract concentration $\left(\mathrm{mL} \mathrm{g}^{-1}\right)$ to determine the concentration of the extract that reduces the activity by $50 \%\left(\mathrm{EC}_{50}\right)$.

\section{Antimicrobial activity}

The antimicrobial activity was determined against Gram (+) bacteria: Clostridium perfringens ATCC 19404, Bacillus cereus ATCC 8739, Listeria monocytogenes ATCC 7644, Staphylococcus aureus ATCC 8538, Sarcina lutea ATCC 9341, and Micrococcus flavus ATCC 40240; Gram (-) bacteria: Escherichia coli ATCC 25922, Pseudomonas aeruginosa ATCC 9027, Salmonella enteritidis ATCC 13076, Shigella sonnei ATCC 25931, Klebsiella pneumoniae ATCC 10031, and Proteus vulgaris ATCC 8427; and yeast: Candida albicans ATCC 10231. All of these were obtained from the American Type Culture Collection. The bacterial strain inocula were prepared from overnight broth cultures, and suspensions were adjusted to $0.5 \mathrm{McFarland}$ standard turbidity (corresponding to $10^{7}$ to $10^{8} \mathrm{CFU} / \mathrm{mL}$ ).

The disc diffusion method was carried out using $100 \mu \mathrm{L}$ of bacterial suspension on Mueller-Hinton agar (MHA, Torlak) in Petri dishes (diameter $90 \mathrm{~mm}$ ). The discs (HiMedia Laboratories Pvt. Limited) were covered with the test samples $(50 \mu \mathrm{L})$ with a concentration of $0.1 \mathrm{~g} / \mathrm{mL}$ and placed into the inoculated agar $(20 \mathrm{~mL})$. The inoculated plates were kept for $24 \mathrm{~h}$ at $37^{\circ} \mathrm{C}$. Chloramphenicol $(30 \mu \mathrm{g} / \mathrm{disc})$, streptomycin $(30 \mu \mathrm{g} / \mathrm{disc})$ and tetracycline $(30 \mu \mathrm{g} / \mathrm{disc})$ were used as positive controls, and the solvent (methanol $-50 \mu \mathrm{L} /$ disc) was treated as a negative control (Radovanović et al.,
2017). As expected, methanol showed no inhibitory activity. All tests were performed in triplicate. Antibacterial activity was represented as the zone of inhibition (in $\mathrm{mm}$ ) against bacterial strains.

\section{Statistical analysis}

All the experiments were performed in triplicate. Values are presented as means \pm standard deviation. Principal component analysis (PCA) and agglomerative hierarchical clustering (AHC) were performed using statistical applications available for Microsoft Excel $^{\circledR}$ (XLSTAT 2018) (Addinsoft, 2018). XLSTAT 2018 was also used to perform the Pearson correlation analysis.

\section{RESULTS AND DISCUSSION \\ Polyphenolic profile}

The spectrophotometric analysis of the obtained seed, skin, stem, leaf and pomace extracts provides fast information on the total polyphenolic contents in the tested by-products (Table 1). The highest content of polyphenols was in the seed extracts obtained from the Merlot and Vranac grape pomace (105.16 and $113.25 \mathrm{mg} / \mathrm{g}$, respectively), followed by that in the extracts of the leaves $(93.31$ and $88.42 \mathrm{mg} / \mathrm{g}$, respectively), the stems ( 78.34 and $73.99 \mathrm{mg} / \mathrm{g}$, respectively), the pomace (58.06 and $67.40 \mathrm{mg} / \mathrm{g}$, respectively), and the skins (50.36 and $51.73 \mathrm{mg} / \mathrm{g}$, respectively). A significantly higher polyphenol content was found in the seed extracts in relation to the other extracts, which agrees with the published data for other varieties (Revilla \& Ryan, 2000; Jayaprakasha et al., 2003; Baydar et al., 2006; Poudel et al., 2008).

To determine the polyphenolic content and composition of the investigated by-products more precisely, the HPLC method was used. The results (Table 2) agree well with those obtained by spectrophotometric determination of the total polyphenol content (Table 1).

The highest sum of phenolic acids, flavonols and flavan3-ols determined by HPLC was in the Merlot and Vranac seed extracts (44.53 and $43.29 \mathrm{mg} / \mathrm{g}$, respectively), followed by the leaves ( 35.41 and $34.71 \mathrm{mg} / \mathrm{g}$, respectively), the stems

TABLE 1

Total phenols (mg GAE/g) and antioxidant activity (mg/L) of Merlot and Vranac waste

\begin{tabular}{llll}
\hline Grape waste & Variety & Total phenols & Antioxidant activity, EC $_{\mathbf{5 0}}$ \\
\hline \multirow{2}{*}{ Seeds } & Merlot & $105.16 \pm 0.93$ & $0.41 \pm 0.02$ \\
& Vranac & $113.25 \pm 0.89$ & $0.37 \pm 0.01$ \\
Skins & Merlot & $50.36 \pm 0.20$ & $2.11 \pm 0.09$ \\
& Vranac & $51.73 \pm 0.19$ & $2.02 \pm 0.07$ \\
Stems & Merlot & $78.34 \pm 0.40$ & $0.81 \pm 0.08$ \\
& Vranac & $73.99 \pm 0.28$ & $0.73 \pm 0.06$ \\
Pomace & Merlot & $58.06 \pm 0.31$ & $1.20 \pm 0.02$ \\
& Vranac & $67.40 \pm 0.38$ & $1.16 \pm 0.03$ \\
Leaves & Merlot & $93.31 \pm 0.76$ & $0.72 \pm 0.03$ \\
& Vranac & $88.42 \pm 0.58$ & $0.66 \pm 0.01$ \\
\hline
\end{tabular}

Data are expressed as mean $\pm \operatorname{SD}(n=3)$. 
TABLE 2

Phenolic compounds (mg/g) of Merlot and Vranac waste, determined by HPLC analysis

\begin{tabular}{|c|c|c|c|c|c|c|}
\hline Phenolic compound & & Seeds & Skins & Stems & Pomace & Leaves \\
\hline \multirow{2}{*}{ Gallic acid } & $\mathrm{M}^{\mathrm{a}}$ & $3.21 \pm 0.07$ & $1.36 \pm 0.03$ & $1.58 \pm 0.03$ & $3.28 \pm 0.08$ & $0.65 \pm 0.02$ \\
\hline & $\mathrm{V}^{\mathrm{b}}$ & $3.13 \pm 0.03$ & $1.40 \pm 0.02$ & $1.43 \pm 0.04$ & $3.33 \pm 0.07$ & $0.33 \pm 0.01$ \\
\hline \multirow{2}{*}{$t$-Caftaric acid } & $\mathrm{M}$ & nd & nd & nd & nd & $9.34 \pm 0.10$ \\
\hline & $\mathrm{V}$ & nd & nd & nd & nd & $7.78 \pm 0.14$ \\
\hline \multirow{2}{*}{$t$-Coutaric acid } & $\mathrm{M}$ & nd & $0.31 \pm 0.03$ & nd & $0.37 \pm 0.03$ & $0.79 \pm 0.06$ \\
\hline & $\mathrm{V}$ & nd & $0.44 \pm 0.10$ & nd & $0.41 \pm 0.02$ & $0.81 \pm 0.10$ \\
\hline \multirow{2}{*}{ Caffeic acid } & $\mathrm{M}$ & nd & $0.35 \pm 0.03$ & nd & $0.42 \pm 0.04$ & $0.75 \pm 0.06$ \\
\hline & $\mathrm{V}$ & nd & $0.38 \pm 0.02$ & nd & $0.50 \pm 0.04$ & $0.68 \pm 0.02$ \\
\hline \multirow{2}{*}{ Chlorogenic acid } & $\mathrm{M}$ & nd & nd & nd & nd & $0.23 \pm 0.03$ \\
\hline & $\mathrm{V}$ & nd & nd & nd & nd & $0.68 \pm 0.02$ \\
\hline \multirow{2}{*}{ Quercetin gl. } & $\mathrm{M}$ & nd & $0.11 \pm 0.01$ & $1.07 \pm 0.03$ & $0.09 \pm 0.01$ & $9.78 \pm 0.11$ \\
\hline & $\mathrm{V}$ & nd & $0.13 \pm 0.01$ & $1.11 \pm 0.03$ & $0.11 \pm 0.01$ & $9.61 \pm 0.13$ \\
\hline \multirow{2}{*}{ Rutin } & $\mathrm{M}$ & nd & $0.15 \pm 0.02$ & $1.33 \pm 0.04$ & $0.11 \pm 0.02$ & $5.32 \pm 0.09$ \\
\hline & $\mathrm{V}$ & nd & $0.14 \pm 0.01$ & $1.40 \pm 0.07$ & $0.15 \pm 0.01$ & $5.71 \pm 0.10$ \\
\hline \multirow{2}{*}{ Luteolin gl. } & $\mathrm{M}$ & nd & $0.09 \pm 0.01$ & nd & $0.04 \pm 0.01$ & nd \\
\hline & $\mathrm{V}$ & nd & $0.11 \pm 0.02$ & nd & $0.06 \pm 0.02$ & nd \\
\hline \multirow{2}{*}{ Myricetin gl. } & $\mathrm{M}$ & nd & $0.09 \pm 0.01$ & nd & nd & nd \\
\hline & $\mathrm{V}$ & nd & $0.08 \pm 0.01$ & nd & nd & nd \\
\hline \multirow{2}{*}{ Kaempferol gl. } & $\mathrm{M}$ & nd & $0.08 \pm 0.01$ & $0.91 \pm 0.03$ & $0.06 \pm 0.01$ & $2.44 \pm 0.09$ \\
\hline & $\mathrm{V}$ & nd & $0.07 \pm 0.01$ & $0.88 \pm 0.04$ & $0.08 \pm 0.01$ & $2.77 \pm 0.05$ \\
\hline \multirow{2}{*}{ Quercetin } & $\mathrm{M}$ & nd & $0.04 \pm 0.01$ & $0.14 \pm 0.01$ & $0.04 \pm 0.01$ & $0.54 \pm 0.01$ \\
\hline & $\mathrm{V}$ & nd & $0.05 \pm 0.01$ & $0.12 \pm 0.01$ & $0.05 \pm 0.01$ & $0.66 \pm 0.03$ \\
\hline \multirow{2}{*}{$(+)$-Catechin } & M & $7.62 \pm 0.09$ & $1.89 \pm 0.04$ & $2.31 \pm 0.06$ & $3.64 \pm 0.12$ & $2.01 \pm 0.04$ \\
\hline & $\mathrm{V}$ & $8.08 \pm 0.11$ & $2.02 \pm 0.07$ & $2.55 \pm 0.05$ & $3.84 \pm 0.12$ & $2.08 \pm 0.03$ \\
\hline \multirow{2}{*}{ (-)-Epicatechin gallate } & $\mathrm{M}$ & $15.50 \pm 0.13$ & $8.95 \pm 0.09$ & $7.27 \pm 0.10$ & $10.60 \pm 0.13$ & nd \\
\hline & $\mathrm{V}$ & $13.88 \pm 0.14$ & $9.08 \pm 0.11$ & $6.55 \pm 0.11$ & $10.58 \pm 0.12$ & nd \\
\hline \multirow{2}{*}{ (-)-Epicatechin } & $\mathrm{M}$ & $10.34 \pm 0.12$ & nd & $2.46 \pm 0.03$ & $1.17 \pm 0.03$ & $3.56 \pm 0.03$ \\
\hline & $\mathrm{V}$ & $10.60 \pm 0.13$ & nd & $2.60 \pm 0.03$ & $1.22 \pm 0.05$ & $3.60 \pm 0.05$ \\
\hline \multirow{2}{*}{ Procyanidin $\mathrm{B}_{2}$} & $\mathrm{M}$ & $7.86 \pm 0.10$ & $4.64 \pm 0.03$ & $3.38 \pm 0.03$ & nd & nd \\
\hline & $\mathrm{V}$ & $7.60 \pm 0.09$ & $4.71 \pm 0.05$ & $3.60 \pm 0.02$ & nd & nd \\
\hline \multirow{2}{*}{ Delphinidin-3-glucoside } & M & nd & $1.83 \pm 0.03$ & nd & $0.95 \pm 0.03$ & nd \\
\hline & $\mathrm{V}$ & nd & $1.60 \pm 0.01$ & nd & $1.03 \pm 0.02$ & nd \\
\hline \multirow{2}{*}{ Cyanidin-3-glucoside } & $\mathrm{M}$ & nd & $1.28 \pm 0.03$ & nd & $0.20 \pm 0.01$ & nd \\
\hline & $\mathrm{V}$ & nd & $1.44 \pm 0.02$ & nd & $0.27 \pm 0.01$ & nd \\
\hline \multirow{2}{*}{ Petunidin-3-glucoside } & $\mathrm{M}$ & nd & $0.60 \pm 0.03$ & nd & $0.28 \pm 0.03$ & nd \\
\hline & $\mathrm{V}$ & nd & $0.58 \pm 0.01$ & nd & $0.24 \pm 0.02$ & nd \\
\hline \multirow{2}{*}{ Peonidin-3-glucoside } & M & nd & $2.73 \pm 0.03$ & nd & $0.13 \pm 0.03$ & nd \\
\hline & $\mathrm{V}$ & nd & $2.60 \pm 0.03$ & nd & $0.11 \pm 0.01$ & nd \\
\hline \multirow{2}{*}{ Malvidin-3-glucoside } & $\mathrm{M}$ & nd & $24.47 \pm 0.19$ & nd & $1.12 \pm 0.03$ & nd \\
\hline & $\mathrm{V}$ & nd & $25.02 \pm 0.17$ & nd & $1.36 \pm 0.02$ & nd \\
\hline
\end{tabular}

${ }^{\mathrm{a}}$ Merlot; ${ }^{\mathrm{b}}$ Vranac; Data are expressed as mean $\pm \mathrm{SD}(n=3) ; \mathrm{nd}=$ not detected 
and pomace (from 19.45 to $20.33 \mathrm{mg} / \mathrm{g}$ ), and the skins (18.06 and $18.61 \mathrm{mg} / \mathrm{g}$, respectively). The main compounds in the seeds were flavan-3-ols (41.32 and $40.16 \mathrm{mg} / \mathrm{g}$, respectively) and gallic acid (3.21 and $3.13 \mathrm{mg} / \mathrm{g}$, respectively).

The skin extracts were rich in anthocyanins (30.91 and $31.24 \mathrm{mg} / \mathrm{g}$, respectively) and flavan-3-ols (15.48 and 15.81 $\mathrm{mg} / \mathrm{g}$, respectively). Malvidin-3-glucoside was the main anthocyanin found in the skins and grape pomace, followed by peonidin-, delphinidin-, cyanidin- and petunidin-3glucosides. The grape pomace also showed a higher content of flavan-3-ols (15.41 and $15.64 \mathrm{mg} / \mathrm{g}$, respectively) and significantly small contents of phenolic acids (4.07 and 4.24 $\mathrm{mg} / \mathrm{g}$, respectively) and anthocyanins $(2.68$ and $3.01 \mathrm{mg} / \mathrm{g}$, respectively). A similar content of phenolic compounds in the seeds and skins has been found by other authors (Iacopini et al., 2008; Anastasiadi et al., 2009; Butkhup et al., 2010; Katalinić et al., 2010; Scola et al., 2010).

HPLC analysis of the extracts of the stems showed that they were also rich in flavan-3-ols (14.42 and $15.30 \mathrm{mg} / \mathrm{g}$, respectively) and contained small amounts of flavonols (3.45 and $3.51 \mathrm{mg} / \mathrm{g}$, respectively). Souquet et al. (2000) reported a similar composition of an extract of Merlot stems in France, and Anastasiadi et al. (2009) in some Greek grape varieties.

The highest flavonol content was found in the extract of leaves (18.08 and $18.75 \mathrm{mg} / \mathrm{g}$, respectively), especially a significant amount of quercetin glucoside (9.78 and 9.61 $\mathrm{mg} / \mathrm{g}$, respectively), rutin (5.32 and $5.71 \mathrm{mg} / \mathrm{g}$, respectively) and kaempferol glucoside (2.44 and $2.77 \mathrm{mg} / \mathrm{g}$, respectively), which is in good agreement with the data in the literature (Monagas et al., 2006; Dani et al., 2010). The investigated leaves also had a high content of phenolic acids (11.76 and $10.28 \mathrm{mg} / \mathrm{g}$, respectively), especially trans-caftaric acid (9.34 and $7.78 \mathrm{mg} / \mathrm{g}$, respectively).

\section{Antioxidant activity}

All the investigated extracts showed strong antioxidant activity (Table 1). Extracts of Vranac were slightly stronger antioxidants $\left(\mathrm{EC}_{50}\right.$ from 0.37 to $\left.2.02 \mathrm{mg} / \mathrm{L}\right)$ than extracts from Merlot $\left(\mathrm{EC}_{50}\right.$ from 0.41 to $\left.2.11 \mathrm{mg} / \mathrm{L}\right)$. The highest antioxidant activity was shown in the seed extracts $(0.37$ and $0.41 \mathrm{mg} / \mathrm{L}$, respectively), followed by extracts of the leaf $(0.66$ and $0.72 \mathrm{mg} / \mathrm{L}$, respectively), stem $(0.81$ and $0.73 \mathrm{mg} / \mathrm{L}$, respectively), pomace (1.16 and $1.20 \mathrm{mg} / \mathrm{L}$, respectively) and skin (2.11 and $2.02 \mathrm{mg} / \mathrm{L}$, respectively). The strong antioxidant activity of seed extracts corresponds to the highest polyphenol content and suggests that the phenolic compounds are partially responsible for the strong antioxidant activity of these extracts. The pomace and skin extracts showed slightly weaker antioxidant activity compared to the rest of the extracts, which has also been observed by others (Baydar et al., 2006; Poudel et al., 2008).

The investigated extracts showed scavenging free radical activity, which was in very good correlation with the content of total polyphenols as determined by spectrophotometric analysis ( $0.9239 \pm 0.2789$ and $0.9258 \pm 0.2657$, respectively), and with the concentration of total flavonoids determined by HPLC analysis $(0.7795 \pm 0.4402$ and $0.7804 \pm 0.4559$, respectively). The data in the literature also confirm the antioxidant activity of the seed, leaf and stem extracts and the correlation with polyphenols (Jayaprakasha et al., 2003; Bartolome et al., 2004; Spigno \& De Faveri, 2007).

\section{Antimicrobial activity}

The data on the antimicrobial activity of all the investigated extracts and three antibiotics (positive control) against Clostridium perfringens, Bacillus cereus, Listeria monocytogenes, Staphylococcus aureus, Sarcina lutea and Micrococcus flavus (Gram-positive strains), Escherichia

TABLE 3

Antimicrobial activities (inhibition zone diameters, $\mathrm{mm}$ ) of Merlot and Vranac by-products ( $50 \mu \mathrm{L} /$ disc) and reference antibiotics $(30 \mu \mathrm{g} /$ disc) against Gram-positive strains

\begin{tabular}{|c|c|c|c|c|c|c|c|}
\hline \multicolumn{2}{|c|}{$\begin{array}{l}\text { Grape by- } \\
\text { product }\end{array}$} & \multirow{2}{*}{$\begin{array}{l}\text { C. perfringens } \\
17.7 \pm 1.3\end{array}$} & \multirow{2}{*}{$\begin{array}{l}\text { B. cereus } \\
17.1 \pm 1.0\end{array}$} & \multirow{2}{*}{$\begin{array}{c}\text { S. aureus } \\
18.3 \pm 1.2\end{array}$} & \multirow{2}{*}{$\begin{array}{l}\text { L. monocytogenes } \\
18.5 \pm 0.9\end{array}$} & \multirow{2}{*}{$\begin{array}{l}\text { S. lutea } \\
19.4 \pm 1.3\end{array}$} & \multirow{2}{*}{$\begin{array}{c}\text { M. flavus } \\
16.7 \pm 1.2\end{array}$} \\
\hline Sord & $\mathrm{M}^{\mathrm{a}}$ & & & & & & \\
\hline Seeas & $\mathrm{V}^{\mathrm{b}}$ & $17.5 \pm 1.2$ & $17.1 \pm 1.2$ & $18.4 \pm 1.3$ & $18.5 \pm 1.3$ & $19.6 \pm 1.0$ & $16.9 \pm 1.1$ \\
\hline \multirow{2}{*}{ Skins } & $\mathrm{M}$ & $16.7 \pm 1.3$ & $16.2 \pm 1.0$ & $17.2 \pm 1.0$ & $17.3 \pm 1.0$ & $18.1 \pm 1.2$ & $15.7 \pm 1.1$ \\
\hline & $\mathrm{V}$ & $16.9 \pm 1.0$ & $16.3 \pm 1.2$ & $17.4 \pm 1.0$ & $17.2 \pm 1.0$ & $18.5 \pm 1.2$ & $15.6 \pm 1.3$ \\
\hline \multirow{2}{*}{ Stems } & $\mathrm{M}$ & $17.2 \pm 1.3$ & $16.8 \pm 1.3$ & $18.2 \pm 1.2$ & $18.1 \pm 1.3$ & $19.0 \pm 1.4$ & $16.2 \pm 1.1$ \\
\hline & $\mathrm{V}$ & $17.4 \pm 1.3$ & $16.9 \pm 1.3$ & $18.5 \pm 1.2$ & $18.2 \pm 1.2$ & $19.3 \pm 1.1$ & $16.4 \pm 1.1$ \\
\hline \multirow{2}{*}{ Pomace } & M & $15.9 \pm 1.2$ & $15.2 \pm 1.2$ & $16.3 \pm 1.3$ & $16.4 \pm 1.3$ & $17.3 \pm 1.3$ & $14.8 \pm 1.0$ \\
\hline & $\mathrm{V}$ & $15.9 \pm 1.1$ & $15.3 \pm 1.0$ & $16.5 \pm 1.1$ & $16.4 \pm 1.2$ & $17.3 \pm 1.3$ & $15.1 \pm 1.3$ \\
\hline \multirow{2}{*}{ Leaves } & M & $17.4 \pm 1.2$ & $16.7 \pm 1.1$ & $18.1 \pm 1.1$ & $18.2 \pm 1.2$ & $19.5 \pm 1.1$ & $16.3 \pm 0.9$ \\
\hline & $\mathrm{V}$ & $17.6 \pm 1.3$ & $16.8 \pm 0.9$ & $18.3 \pm 1.3$ & $18.1 \pm 1.0$ & $19.7 \pm 1.3$ & $16.5 \pm 0.8$ \\
\hline \multicolumn{2}{|c|}{ Chloramphenicol } & $\mathrm{nt}$ & $26.0 \pm 1.1$ & $25.0 \pm 1.2$ & $18.0 \pm 2.0$ & $38.0 \pm 2.0$ & $35.0 \pm 2.1$ \\
\hline \multicolumn{2}{|c|}{ Tetracycline } & $29.0 \pm 2.0$ & $23.9 \pm 1.0$ & $18.5 \pm 1.3$ & $18.7 \pm 1.2$ & $20.0 \pm 1.2$ & $23.6 \pm 0.7$ \\
\hline
\end{tabular}

${ }^{\mathrm{a}}$ Merlot; ${ }^{\mathrm{b}}$ Vranac; Data are expressed as mean $\pm \mathrm{SD}(n=3) ; \mathrm{nt}=$ not tested 
TABLE 4

Antimicrobial activities (inhibition zone diameters, $\mathrm{mm})$ of Merlot and Vranac by-products ( $50 \mu \mathrm{L} /$ disc) and reference antibiotics $(30 \mu \mathrm{g} /$ disc $)$ against Gram-negative strains and yeast

\begin{tabular}{llllllll}
\hline $\begin{array}{l}\text { Grape by- } \\
\text { product }\end{array}$ & & E. coli & P. aeruginosa & S. enteritidis & S. sonnei & K. pneumoniae & C. albicans \\
\hline \multirow{2}{*}{ Seeds } & $\mathrm{M}^{\mathrm{a}}$ & $14.8 \pm 0.7$ & $15.6 \pm 0.9$ & $15.1 \pm 1.0$ & $17.4 \pm 1.2$ & $16.1 \pm 1.0$ & $15.2 \pm 1.1$ \\
& $\mathrm{~V}^{\mathrm{b}}$ & $15.7 \pm 1.2$ & $15.9 \pm 1.2$ & $15.4 \pm 1.1$ & $17.5 \pm 1.2$ & $16.1 \pm 1.3$ & $15.5 \pm 0.9$ \\
Skins & $\mathrm{M}$ & $13.0 \pm 1.1$ & $14.4 \pm 1.0$ & $14.0 \pm 1.2$ & $16.3 \pm 1.3$ & $15.7 \pm 1.2$ & $14.3 \pm 1.0$ \\
& $\mathrm{~V}$ & $13.3 \pm 0.7$ & $14.3 \pm 0.9$ & $14.0 \pm 0.8$ & $16.6 \pm 0.8$ & $15.2 \pm 1.4$ & $14.3 \pm 0.9$ \\
Stems & $\mathrm{M}$ & $14.1 \pm 1.2$ & $15.6 \pm 1.3$ & $15.2 \pm 1.1$ & $17.6 \pm 1.3$ & $16.6 \pm 1.1$ & $15.1 \pm 1.0$ \\
& $\mathrm{~V}$ & $14.0 \pm 1.0$ & $15.4 \pm 1.0$ & $15.1 \pm 1.2$ & $17.7 \pm 1.0$ & $16.5 \pm 1.1$ & $15.2 \pm 1.0$ \\
Pomace & $\mathrm{M}$ & $12.1 \pm 0.8$ & $13.5 \pm 1.1$ & $13.0 \pm 0.9$ & $15.8 \pm 1.3$ & $15.0 \pm 1.2$ & $13.1 \pm 0.7$ \\
& $\mathrm{~V}$ & $12.7 \pm 1.2$ & $13.7 \pm 1.2$ & $13.3 \pm 1.0$ & $15.6 \pm 1.3$ & $15.1 \pm 1.3$ & $13.3 \pm 1.3$ \\
Leaves & $\mathrm{M}$ & $14.3 \pm 1.0$ & $15.6 \pm 1.0$ & $15.0 \pm 1.2$ & $17.3 \pm 1.2$ & $16.5 \pm 1.1$ & $15.4 \pm 1.0$ \\
& $\mathrm{~V}$ & $14.7 \pm 1.1$ & $15.9 \pm 1.2$ & $15.1 \pm 1.1$ & $17.7 \pm 1.2$ & $16.6 \pm 1.0$ & $15.5 \pm 1.2$ \\
Streptomycin & & $16.0 \pm 1.2$ & $23.0 \pm 1.0$ & $18.0 \pm 1.0$ & $19.0 \pm 2.0$ & $\mathrm{nt}$ & $\mathrm{nt}$ \\
Tetracycline & & $23.2 \pm 1.2$ & $20.8 \pm 1.5$ & $23.3 \pm 1.3$ & $31.1 \pm 0.8$ & $23.6 \pm 0.6$ & $19.2 \pm 0.5$ \\
\hline
\end{tabular}

${ }^{\mathrm{a}}$ Merlot; ${ }^{\mathrm{b}}$ Vranac; Data are expressed as mean $\pm \mathrm{SD}(n=3) ; \mathrm{nt}=$ not tested

coli, Pseudomonas aeruginosa, Salmonella enteritidis, Shigella sonnei, Klebsiella pneumoniae and Proteus vulgaris (Gram-negative strains) and Candida albicans (yeast) are given in Tables 3 and 4 (inhibition zones).

It was found that the investigated extracts were on average more sensitive to Gram-positive strains compared to Gram-negative strains and yeast, which is in agreement with the data in the literature (Jayaprakasha et al., 2003; Özkan et al., 2004; Scola et al., 2010). We assume that the difference in activity is caused by the different structure of bacterial walls in Gram-positive and Gram-negative bacteria. The values of antimicrobial activity were in agreement with the results of the HPLC analysis (Table 2) (Radovanović et al., 2017). The analysis of the Merlot and Vranac by-products shows that seeds have the highest antimicrobial activity in the range of 16.7 to $19.6 \mathrm{~mm}$ against Gram-positive and 14.8 to $17.5 \mathrm{~mm}$ against Gram-negative strains. The extracts of leaves also show high antimicrobial activity in the range of 16.3 to $19.7 \mathrm{~mm}$ against Gram-positive and 14.3 to 17.7 $\mathrm{mm}$ against Gram-negative strains, followed by extracts of the stems (16.2 to $19.3 \mathrm{~mm}$ against Gram-positive and 14.0 to $17.7 \mathrm{~mm}$ against Gram-negative strains), the extracts of skins (15.6 to $18.5 \mathrm{~mm}$ against Gram-positive and 13.0 to $16.6 \mathrm{~mm}$ against Gram-negative strains), and the extracts of pomace (14.8 to $17.3 \mathrm{~mm}$ against Gram-positive and 12.1 to $15.8 \mathrm{~mm}$ against Gram-negative strains). All of the tested extracts exhibited satisfactory antimicrobial activity against Candida albicans (yeast) - in the range of 13.1 to $15.5 \mathrm{~mm}$.

The highest antimicrobial activity of the investigated extracts was shown against Gram-positive strains: Sarcina lutea, Listeria monocytogenes and Staphylococcus aureus (inhibition zones in the range of 16.3 to $19.7 \mathrm{~mm}$ ), and against the Gram-negative strains Shigella sonnei and Pseudomonas aeruginosa (inhibition zones in the range of 15.0 to 17.7 $\mathrm{mm}$ ). The obtained results are similar to the results of other authors, who perform investigations on different grape varieties against some bacterial strains (Özkan et al., 2004; Baydar et al., 2006; Anastasidi et al., 2009; Butkhup et al., 2010; Katalinić et al., 2010).

\section{Statistical analyses}

Statistical analyses were performed of the correlations among the contents of various classes of polyphenolic compounds in the extracts of both the Merlot and Vranac byproducts, determined by HPLC analysis, and antioxidant (AA) and antimicrobial activities against Gram-positive and Gram-negative bacteria and Candida albicans yeast.

\section{Pearson correlation analysis}

Phenolic acid (PA) and flavonols (FOS) are in a strong positive correlation (0.909) with each other. On the other hand, antioxidant activity (AA) has a medium-negative correlation with the antimicrobial activities of Gram-positive bacteria - L. monocytogenes (LM) (-0.646) and M. flavus (MF) (-0.655), and Gram-negative bacteria - E. coli (EC) (-0.709), P. aeruginosa (PA) (-0.689), S. enteritidis (SE) (-0.650) and $S$. sonnei (SS) (-0.632). The antimicrobial activity of $C$. perfringens $(\mathrm{CP})$ has a strong, positive correlation with the antimicrobial activities of all the investigated bacteria $[B$. cereus (BC) (0.982), S. aureus (SA) (0.972), LM (0.974), SL (0.983), MF (0.962), EC (0.901), PA (0.954), SE (0.956), SS (0.951) and K. pneumoniae (KP) (0.902)]. Similar, strong positive correlations were observed among other Gram-positive and Gram-negative bacteria. 
Principal component analysis (PCA)

In the first step of the statistical evaluation, the KolmogorovSmirnov test (the significance level, $\alpha$, was 0.05 ) was used to test the normality of the data. The data included total phenolic acids, total flavonols, total flavan 3-ols, antioxidant activities and antimicrobial activities (expressed as inhibition zones) obtained for all the investigated Gram-positive and Gram-negative bacteria. Before PCA analysis, the data matrix was tested to detect outliers. Grubb's test was used with the experimental data, and no outliers were found. From the shape of the scree plot, shown in Fig. 1, the number of important components that were used in further calculations can be seen.

The PCA of the dataset revealed the presence of two components with characteristic (Eigen) values (11.224 and 2.381) exceeding 1 . This two-component solution explained a total of $90.697 \%$ of the variance, with $74.826 \%$ contributed by the first component, and $15.871 \%$ by the second compo-

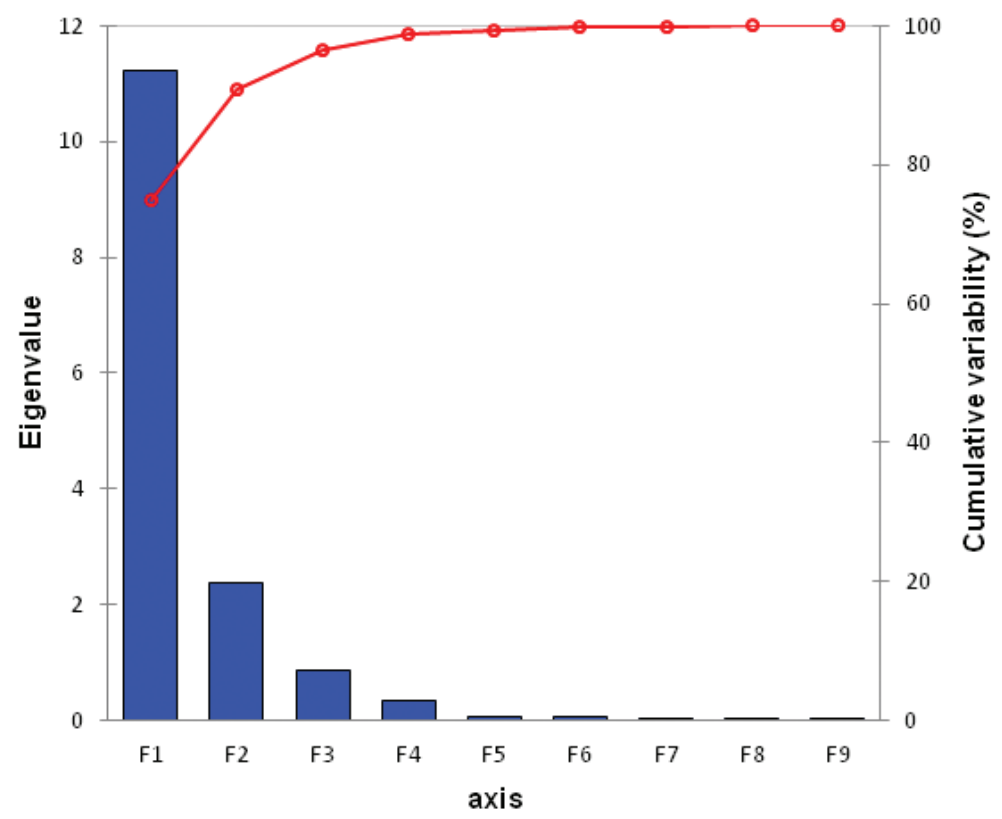

FIGURE 1

Scree plot. In this plot, the eigenvalues are sorted from the largest to the smallest.

a)

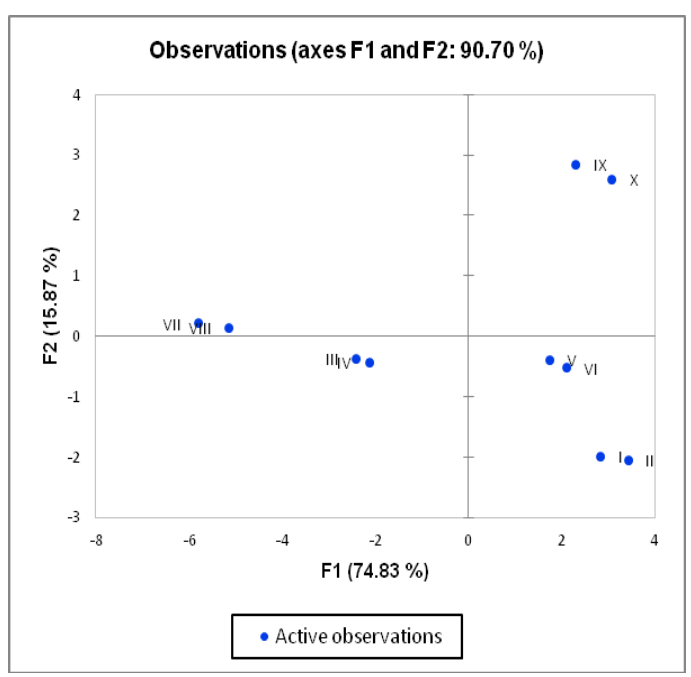

FIGURE 2

Principal component analysis (PCA). a) PCA scree plot of the first major component 1 (PCA1) versus the second component (PC2); b) Loading plot of the first main component (PC1) versus the second component (PC2). Variables: PA - phenolic acids, FOS - flavonols, F3O - flavan-3-ols, AA - antioxidant activity, CP - C. perfringens, BC - B. cereus, SA - S. aureus, LM - L. monocytogenes, SL - S. lutea, MF - M. flavus, EC - E. coli, PA - P. aeruginosa, SE - S. enteritidis, SS - S. sonnei, KP - K. pneumoniae; Samples: I - seeds (Merlot), II - seeds (Vranac), III - skins (Merlot), IV - skins (Vranac), V - stems (Merlot), VI stems (Vranac), VII - pomace (Merlot), VIII - pomace (Vranac), IX - leaves (Merlot), X - leaves (Vranac). 


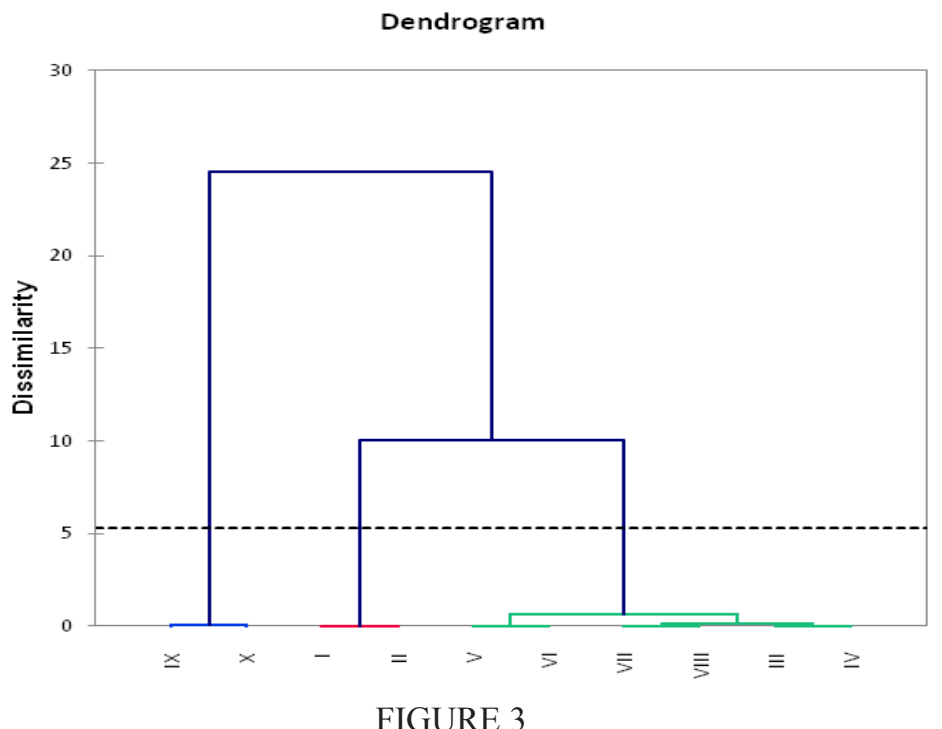

Dendrogram derived from the results obtained on the basis of the extracts of Merlot and Vranac grape varieties. Samples: I - seeds (Merlot), II - seeds (Vranac), III - skins (Merlot), IV - skins (Vranac), V - stems (Merlot), VI - stems (Vranac), VII pomace (Merlot), VIII - pomace (Vranac), IX - leaves (Merlot), X - leaves (Vranac).

nent. The PCA scree plot shows that samples I, II, V, VI, IX and $\mathrm{X}$ (the extracts of seeds, stems and leaves) contained higher concentrations of phenolic acids - the first variable (positive values in PC1), and samples III, IV, VII and VIII (the extracts of skins and pomace) contained lower concentrations of total phenolic acids (negative values in PC1). On the other side, VII to X (pomace and leaf extracts) contained higher concentrations of flavonols, and samples I to VI (seed, skin and stem extracts) contained lower concentrations of flavonols (negative values in PC2) (Fig. 2a). The loading plot shows very similar values for both Gram-positive and Gram-negative bacteria, with AA as the only parameter with a negative value in F1 (Fig. 2b).

\section{Agglomerative hierarchical clustering (AHC)}

Agglomerative hierarchical clustering (AHC) of the standardised variables using the Ward method as an amalgamation rule was performed with the squared Euclidean distance as a measure of the proximity between the samples. The obtained dendrogram presenting the clustering of the analysed samples is presented in Fig. 3.

The dendrogram in Fig. 3 shows that all the monitored samples could be grouped into three main clusters, which are presented using different colours. Cluster I includes samples with concentrations of phenolic acids of more than $10 \mathrm{mg} \mathrm{g}^{-1}$ : IX and X (the extracts of leaves from Merlot and Vranac); cluster II includes samples with no detected flavonols: I and II (the extracts of seeds from Merlot and Vranac), and cluster III includes samples III to VIII (the extracts of skins, stems and pomace from both Merlot and Vranac). Thus, this cluster analysis was not able to distinguish samples based on the grape variety, but it was successful in differentiating among parts of the vine - leaves and seeds show different properties compared to skins and stems, which apparently were the major ingredients in the pomace.

\section{CONCLUSIONS}

The grapevine is a powerful plant that is rich in polyphenol compounds - even in the by-products after the vinification process. Those compounds are responsible for the strong antioxidant and antimicrobial activities of grapes, wines and their by-products. The seeds and leaves had the highest total phenol content and showed the strongest antioxidant and antimicrobial activities. The other extracts - of the stems, skins and pomace - also showed significant antioxidant and antimicrobial activities.

\section{LITERATURE CITED}

Abarghuei, M.J., Rouzbehan Y. \& Alipour D., 2010. The influence of the grape pomace on the ruminal parameters of sheep. Livestock Sci. 132, 7379.

Addinsoft, 2018. XLSTAT 2018: Data analysis and statistical solution for Microsoft Excel. Addinsoft, Paris.

Anastasiadi, M., Chorianopoulos, N.G., Nychas, G.J. \& Haroutounian, S.A., 2009. Antilisterial activities of polyphenol-rich extracts of grapes and vinification byproducts. J. Agric. Food Chem. 57, 457-463.

Andjelković, M., Milenković-Andjelković, A., Radovanović, B. \& Radovanović A., 2014. Optimization of ultrasound-assisted extraction of phenols from seeds of grape pomace. Acta Chim. Slov. 61, 858-865.

Andjelković, M., Radovanović, B., Radovanović, A. \& MilenkovićAndjelković, A., 2013. Changes in polyphenolic content and antioxidant activity of grapes cv. Vranac during ripening. S. Afr. J. Enol. Vitic. 34(2), 147-155.

Baiano, A. \& Terracone, C., 2012. Varietal differences among the phenolic profiles and antioxidant activities of seven table grape cultivars grown in the south of Italy based on chemometrics. J. Agric. Food Chem. 59, 9815-9826.

Bartolome, B., Nunez, V., Monagas, M. \& Gomez-Cordoves C. 2004. In vitro antioxidant activity of red grape skins. Eur. Food Res. Technol. 218, 173-177. 
Baydar, N.G., Sagdic, O., Özkan, G. \& Cetin S. 2006. Determination of antibacterial effects and total phenolic contents of grape (Vitis vinifera L.) seed extracts. Int. J. Food Sci. Technol. 41, 799-804.

Brenes, A., Viveros, A., Chamorro, S. \& Arija I., 2016. Use of polyphenolrich grape by-products in monogastric nutrition. A review. Anim. Feed Sci. Tech. 211, 1-17.

Butkhup, L., Chowtivannakul, S., Gaensakoo, R., Prathepha, P. \& Samappito S., 2010. Study of the phenolic composition of Shiraz red grape cultivar (Vitis vinifera L.) cultivated in North-Eastern Thailand and its antioxidant and antimicrobial activity. S. Afr. J. Enol. Vitic. 31, 89-98.

Christ, K.L. \& Burritt, R.L., 2013. Critical environmental concerns in wine production: An integrative review. J. Clean Prod. 53, 232-242.

Cuccia, P., 2015. Ethics + economy + environment $=$ sustainability: Gambero Rosso on the front lines with a new concept of sustainability. Wine Econ. Pol. 4, 69-70.

Dani, C., Oliboni, L.S., Agostini, F., Serafini, C., Henriques, J.A. \& Salvador, M., 2010. Phenolic content of grapevine leaves (Vitis labrusca var. Bordo) and its neuroprotective effect against peroxide damage. Toxic in Vitro 24, 148-153.

Dwyer, K., Hosseinian, F. \& Rod, M., 2014. The market potential of grape waste alternatives. J. Food Res. 3(2), 91-106.

Iacopini, P., Baldi, M., Storchi, P. \& Sebastiani, L., 2008. Catechin, epicatechin, quercetin, rutin and resveratrol in red grape: Content, in vitro antioxidant activity and interactions. J. Food Comp. Anal. 21, 589-598.

Jayaprakasha, G.K., Selvi, T. \& Sakariah, K.K., 2003. Antibacterial and antioxidant activities of grape (Vitis vinifera) seed extracts. Food Res. Int $36,117-122$.

Katalinić, V., Mozina, S.S., Skroza, D., Generalić, I., Abramović, H., Milos, M., Ljubenkov, I., Piskernik, S., Pezo, I., Terpinc, P. \& Boban, M., 2010 Polyphenolic profile, antioxidant properties and antimicrobial activity of grape skin extracts of 14 Vitis vinifera varieties grown in Dalmatia (Croatia). Food Chem. 119, 715-723.

Ky, I., Lorrain, B., Kolbas, N., Crozier, A. \& Teissedre, P.I., 2014. Wine by-products: Phenolic characterization and antioxidant activity evaluation of grapes and grape pomaces from six different French grape varieties. Molecules 19, 482-506.

Lingua, M.S., Fabani, M.P., Wunderlin, D.A. \& Baroni, M.V., $2016 a$. From grape to wine: Changes in phenolic composition and its influence on antioxidant activity. Food Chem. 208, 228-238.

Lingua, M.S., Fabani, M.P., Wunderlin, D.A. \& Baroni, M.V., 2016b. In vivo antioxidant activity of grape, pomace and wine from three varieties grown in Argentina: Its relationship to phenolic profile. J. Funct. Foods 20, 332-345.

Mazza, G., Fukumoto, P., Delaquis, B., Girard, B. \& Ewert, B., 1999. Anthocyanins, phenolics, and color of Cabernet Franc, Merlot, and Pinot Noir wines from British Columbia. J. Agric. Food Chem. 47, 4009-4017.

Monagas, M., Hernandez-Ledesma, B., Gomez-Cordoves, C. \& Bartolome, B., 2006. Commercial dietary ingredients from Vitis vinifera L. leaves and grape skins: Antioxidant and chemical characterization. J. Agric. Food Chem. 54, 319-327

Muñoz, P., Morales, M.P., Mendivil, M.A., Juarez, M.C. \& Muñoz, L., 2014. Using of waste pomace from winery industry to improve thermal insulation of fired clay bricks. Eco-friendly way of building construction. Constr. Build. Mater. 71, 181-187.

OIV, 2019. http://www.oiv.int/en/databases-and-statistics/statistics [accessed 4 May 2019].
Özkan, G., Sagdiç, O., Baydar, N.G. \& Kurumahmutoglu, Z., 2004 Antibacterial activities and total phenolic contents of grape pomace extracts. J. Sci. Food Agric. 84, 1807-1811.

Parry, J.W., Li, H., Liu, J.-R., Zhou, K., Zhang, L. \& Ren, S. 2011. Antioxidant activity, antiproliferation of colon cancer cells, and chemical composition of grape pomace. Food Nutr. Sci. 2, 530-540.

Poudel, P.R., Tamura, H., Kataoka, I. \& Mochioka, R. 2008. Phenolic compounds and antioxidant activities of skins and seeds of five wild grapes and two hybrids native to Japan. J. Food Comp. Anal. 21, 622-625.

Radovanović, A., Arsic, B., Radovanović, V., Jovančićević, B. \& Nikolic, V., 2017. Broad spectrum of antimicrobial properties of commercial wines from different Vitis vinifera L. varieties. World J. Microbiol. Biotechnol. 33, article 18. doi:10.1007/s11274-016-2183-4

Radovanović, A., Jovančićević, B., Arsic, B., Radovanović, B. \& Gojkovic Bukarica, Lj., 2016. Application of non-supervised pattern recognition techniques to classify Cabernet Sauvignon wines from the Balkan region based on individual phenolic compounds. J. Food Comp. Anal. 49, 42-48.

Radovanović, A.N., Jovančićević, B.S., Radovanović, B.C., MihajilovKrstev, T. \& Zvezdanović, J.B., 2012. Antioxidant and antimicrobial potentials of Serbian red wines produced from international Vitis vinifera grape varieties. J. Sci. Food Agric. 92, 2154-2161.

Radovanović, B.C., Radovanović, A.N. \& Souquet, J.-M., 2010. Phenolic profile and free radical-scavenging activity of Cabernet Sauvignon wines of different geographical origins from the Balkan region. J. Sci. Food Agric. $90,2455-2461$

Revilla, E. \& Ryan, J.-M., 2000. Analysis of several phenolic compounds with potential antioxidant properties in grape extracts and wines by highperformance liquid chromatography-photodiode array detection without sample preparation. J. Chrom. A 881, 461-469.

Rockenbach, I.I., Rodrigues, E., Gonzaga, L.V., Caliari, V., Genovese, M.I., De Souza Schmidt Gonçalves, A.E. \& Fett, R. 2011. Phenolic compounds and antioxidant activity in pomace from selected red grapes (Vitis vinifera L. and Vitis labrusca L.) widely produced in Brazil. Food Chem. 127(1), 174-179.

Rostagno, M.A., Palma, M. \& Barroso C.G., 2003. Ultrasound-assisted extraction of soy isoflavones. J. Chromatogr. A. 1012(2), 119-128.

Santos, F.T., Goufo, P., Santos, C., Botelho, D., Fonseca, J., Queiros, A., Costa, M.S.S.M. \& Trindade, H., 2016. Comparison of five agro-industrial waste-based composts as growing media lettuce: Effect on yield, phenolic compounds and vitamin C. Food Chem. 209, 293-301.

Scola, G., Conte, D., Spada, P.W., Dani, C., Vanderlinde, R., Funchal, C. \& Salvador, M., 2010. Flavan-3-ol compounds from wine wastes with in vitro and in vivo antioxidant activity. Nutrients 2, 1048-1059.

Shinagawa, F.B., De Santana, F.C., Torres, L.R.O. \& Mancini-Filho, J., 2015. Grape seed oil: A potential functional food? Food Sci. Techn. 35, $399-406$.

Souquet, J.-M., Labarbe, B., Le Guerneve, C., Cheynier, V. \& Moutounet, M., 2000. Phenolic composition of grape stems. J. Agric. Food Chem. 48 , 1076-1080

Spigno, G. \& De Faveri, D.M., 2007. Antioxidants from grape stalks and marc: Influence of extraction procedure on yield, purity and antioxidant power of the extracts. J. Food Eng. 78, 793-801.

Wang, J., Sun, B., Cao, Y., Tian, Y. \& Li, X., 2008. Optimisation of ultrasound-assisted extraction of phenolic compounds from wheat bran. Food Chem. 106, 804-810. 